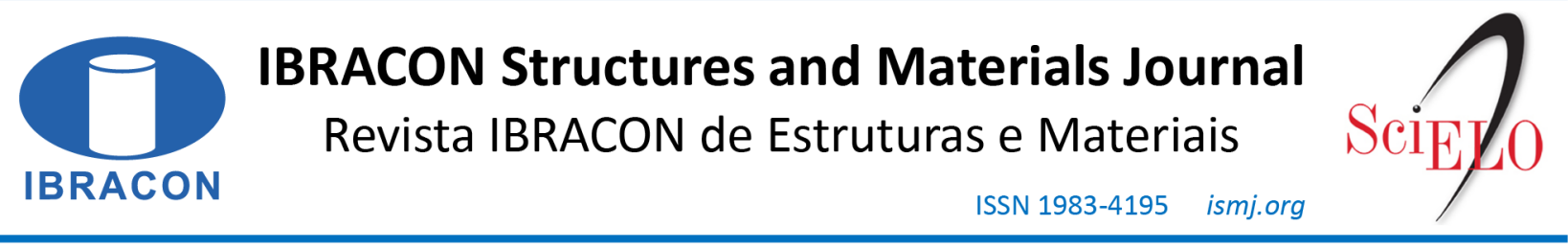

ORIGINAL ARTICLE

\title{
Predicting the mechanical properties of lightweight aggregate concrete using finite element method
}

\section{Determinação de propriedades mecânicas de concreto com agregado leve via método dos elementos finitos}

\author{
Aldemon Lage Bonifácio ${ }^{a}$ \\ Julia Castro Mendes ${ }^{\mathrm{b}}$ \\ Michèle Cristina Resende Farage ${ }^{\mathrm{a}}(\mathrm{D})$ \\ Flávio de Souza Barbosa ${ }^{\mathrm{a}}$ (D) \\ Anne-Lise Beaucour ${ }^{\mathbb{B}}$
}

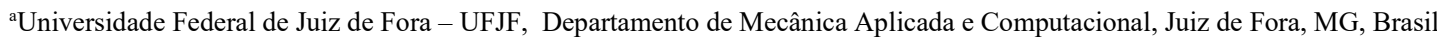

bUniversidade Federal de Ouro Preto - UFOP, Departamento de Engenharia Civil, Ouro Preto, MG, Brasil

${ }^{c}$ Université de Cergy-Pontoise, Département de Génie Civil, Cergy-Pontoise, France
\end{abstract}

Received 01 July 2019

Accepted 03 February 2020

\begin{abstract}
The compressive strength $\left(\mathrm{f}_{\mathrm{c}}\right)$ and Young's modulus $\left(\mathrm{E}_{\mathrm{c}}\right)$ of concretes are properties of great importance in civil engineering problems. To this day, despite the relevance of the subject, concretes are still designed based on charts and empirical formulae. This scenario is even more imprecise for lightweight aggregate concretes (LWAC), which contain less design methodologies and case studies available in the literature. In this sense, the present work presents a numerical simulation for predicting the properties of LWAC's specimens using the Finite Element Method. The material was considered as biphasic, comprising lightweight aggregates and the enveloping mortar. Each phase was modelled with its own compressive strength, tensile strength and Young's modulus. The achieved numerical results for $f_{c}$ and $E_{c}$ were compared with their experimental counterparts, obtained from the literature. In total, 48 concrete formulations were assessed. Numerical results showed fair agreement with the experimental data. In general, the Mean Absolute Percentage Error (MAPE) was lower for the shale aggregates for both Young's modulus ( $1.75 \%$ versus $4.21 \%$ of expanded clay) and compressive strength ( $4.19 \%$ versus $9.89 \%$ of expanded clay). No clear trend of error was identified in relation to the aggregate proportion or to the mortar types, in which the MAPE varied from $2.36 \%$ to $8.13 \%$. In conclusion, the simplification to spherical aggregates has shown satisfactory results, as has the adoption of a 2D model, which require less computational resources. Results encourage further applications with more complex geometrical aspects to improve the mix design and safety of LWAC.
\end{abstract}

Keywords: lightweight aggregate concrete, finite element method, prediction of compressive strength, prediction of elastic modulus.

Resumo: A resistência à compressão (fc) e o módulo de elasticidade (Ec) de concretos são propriedades de grande importância em problemas de engenharia civil. Até o presente momento, apesar da relevância do tema, o traço de concretos ainda é projetado com base em métodos gráficos e fórmulas empíricas. Esse cenário é ainda mais impreciso para concretos leves estruturais de agregados leves (LWAC), que possuem ainda menos metodologias de traço e estudos de caso disponíveis na literatura. Dessa forma, este trabalho apresenta uma simulação numérica para prever as propriedades de corpos de prova de LWAC usando o Método dos Elementos Finitos. O material foi considerado bifásico, incluindo os agregados leves e a argamassa envolvente. Cada fase foi modelada com sua própria resistência à compressão, resistência à tração e módulo de elasticidade. Os resultados numéricos obtidos para fc e Ec foram comparados com seus equivalentes experimentais, obtidos da literatura. No total 48 traços de concreto foram investigados. Os resultados numéricos mostraram uma correlação satisfatória com os dados experimentais. Em geral, o erro médio percentual absoluto (MAPE) foi menor nos agregados de xisto para o módulo de elasticidade $(1,75 \%$ contra

Corresponding author: Aldemon Lage Bonifácio. E-mail: aldemon.bonifacio@engenharia.ufjf.br

Financial support: CAPES (Coordenação de Aperfeiçoamento de Pessoal de Nível Superior, Finance Code 001 - scholarship and PROCAD 88881.068530/2014-0), FAPEMIG (Fundação de Amparo à Pesquisa do Estado de Minas Gerais, projects APQ-01935-16 and PPM-00106-17), CNPq (Conselho Nacional de Desenvolvimento Científico e Tecnológico, projects 423058/2016-9-APQ and 306686/2015-5-PQ, 311576/2018-4-PQ), UFJF (Universidade Federal de Juiz de Fora, scholarship). Conflict of interest: Nothing to declare. 
$4,21 \%$ da argila expandida) e resistência à compressão (4,19\% contra 9,89\% da argila expandida). Não foi identificada uma tendência clara de erro em relação à proporção de agregado ou aos tipos de argamassa, nos quais o MAPE variou de 2,36\% a $8,13 \%$. Concluindo, a simplificação para agregados esféricos mostrou resultados satisfatórios, assim como a adoção de um modelo $2 \mathrm{D}$, que requer menos recursos computacionais. Os resultados encorajam outras aplicações com aspectos geométricos mais complexos para melhorar o design e a segurança de estruturas de LWAC.

Keywords: concreto com agregado leve, método dos elementos finitos, previsão de resistência a compressão, previsão de módulo de elasticidade.

How to cite: A. L. Bonifácio, J. C. Mendes, M. C. R. Farage, F. S. Barbosa, and A. L. Beaucour, "Predicting the mechanical properties of lightweight aggregate concrete using finite element method," Rev. IBRACON Estrut. Mater., vol. 13, no. 4, e13410, 2020, https://doi.org/10.1590/S1983-41952020000400010

\section{INTRODUCTION}

The concrete's compressive strength and Young's modulus are the main mechanical properties that will influence the design, cost, and safety of concrete structures. However, the proportion of materials (or mix design) of concrete is nowadays still performed through charts and empirical formulae [1] [2].

This scenario is even more imprecise for structural lightweight aggregate concretes (LWAC), which uses lightweight aggregates (LWA) in their composition. Common LWAs include pumice and expanded clay, shale or slate, usually manufactured in rotary kilns. This fabrication method generates a material more porous than conventional rock-mined aggregates. Due to their high porosity, they have bulk density lower than $1120 \mathrm{~kg} / \mathrm{m}^{3}$ [3], what reduces the specific weight of LWAC to below $2000 \mathrm{~kg} / \mathrm{m}^{3}$ [4]. Nowadays LWAC is used on a large scale to reduce the self-weight of structures [5]. It also presents transport advantages, allows longer spans and promotes thermoacoustic insulation [6] [7].

Several properties of the aggregates affect the mechanical behavior of concrete - e.g., bulk and specific density, particle shape and texture, particle size distribution, porosity, friability, compressive strength, Young's modulus, chemical composition, among others [8] [2]. Regarding LWA specifically, their absorbent structure allows the use of saturated LWA as an internal reservoir to release water as the concrete cures. This phenomenon promotes to the LWAC a reduced autogenous shrinkage; an increased mechanical interlocking between the matrix and the LWA; and, thus, a negligible interfacial transition zone due to internal curing [9] [10] [11].

In conventional concretes, the aggregate has a higher compressive strength than the mortar and the interfacial transition zone is the weak spot of the composite. Conversely, in LWAC, the aggregate's relatively low strength is the main factor controlling the concrete's fracture [12] [13]. But just like conventional concretes, the mix design of LWAC is based on limited empirical charts and formulae; and its mechanical properties are generally obtained by cost-demanding testing of specimens after a standard curing period of 28 days.

\subsection{Justification}

Since mechanical tests usually demand a significant amount of material and personnel for preparing the specimens and the results are only known after several weeks, several researchers have been studying numerical solutions to evaluate the concrete's properties prior to its mixing [14] [15] [16]. These initiatives have the potential to avoid structural issues in the construction, to reduce labor costs, and to decrease material waste in the laboratory.

To this purpose, some works applied Artificial Intelligence to predict the mechanical properties of LWAC. These are the cases of Altun et al. [17], Alshihri et al. [18], and a previous work by the authors [19], who used neural networks. Although a fast and reliable technique [19], neural networks provide only one single final result based on multiple variables. They do not evaluate the behavior of the concrete during the compressive test, as does the Finite Element Method (FEM), for example. Furthermore, the application of algorithms of Artificial Intelligence normally demands a robust database with a large number of experimental results relating the studied property to its respective mix design formulation.

The same limitations hold for analytical models and regression equations, as the ones developed by Bogas and Gomes [11], Cui et al. [20], and Barbosa et al. [21]. Additionally, the vast majority of prediction studies only focus on compressive strength, neglecting the modulus of elasticity, an imperative property in the design of lightweight structures.

In this sense, seeking to improve the comprehension of LWAC's mechanical properties, the present work presents a numerical simulation of the compressive behavior of LWAC's samples using FEM. It assumes the LWAC as a biphasic composite, composed of mortar and sphere-shaped lightweight aggregates (LWA). An assessment of this methodology is carried out by comparing the achieved numerical results for Young's modulus and compressive strength with their experimental counterparts obtained from the literature. The generalization capacity of the presented method 
is evaluated through the simulation of 48 concrete formulations, including all possible combinations of three types of mortars, four types of aggregates and four different aggregate proportions.

\section{MATERIALS AND EXPERIMENTAL PROGRAM}

\subsection{Materials}

The experimental data used as input and for validation were obtained from an experimental study with cylindrical samples of LWAC. The tests were performed by Ke et al. [22] [23], who analyzed the compressive strength and modulus of elasticity of LWAC samples at 28 days.

In this experimental program, three types of mortars were used: normal (40 MPa), high performance (64 MPa), and very high performance (86 MPa). Regarding the aggregates, four types were used: 4/10-550-A, 4/10-430-A, 4/10-520-S and 4/8-750-S; in which each name matches the characteristic diameters $(\mathrm{d} / \mathrm{D}$, in $\mathrm{mm})$, the bulk density $\left(\mathrm{kg} / \mathrm{m}^{3}\right)$, and the type of aggregate (A - expanded clay, S - expanded shale), respectively. The combination of these materials in proportions of $12.5 \%, 25.0 \%, 37.5 \%$ and $45.0 \%$ of LWA in volume generated 48 different formulations, and over 144 specimens were tested.

The expanded clay LWA 4/10-550-A and 4/10-430-A are nodular aggregates of quasi-spherical shape. On the other hand, the shale aggregates 4/10-520-S and 4/8-750-S are more irregulars and constituted of various types of grains corresponding to different degrees of expansion. Some typical images are shown in Figure 1.

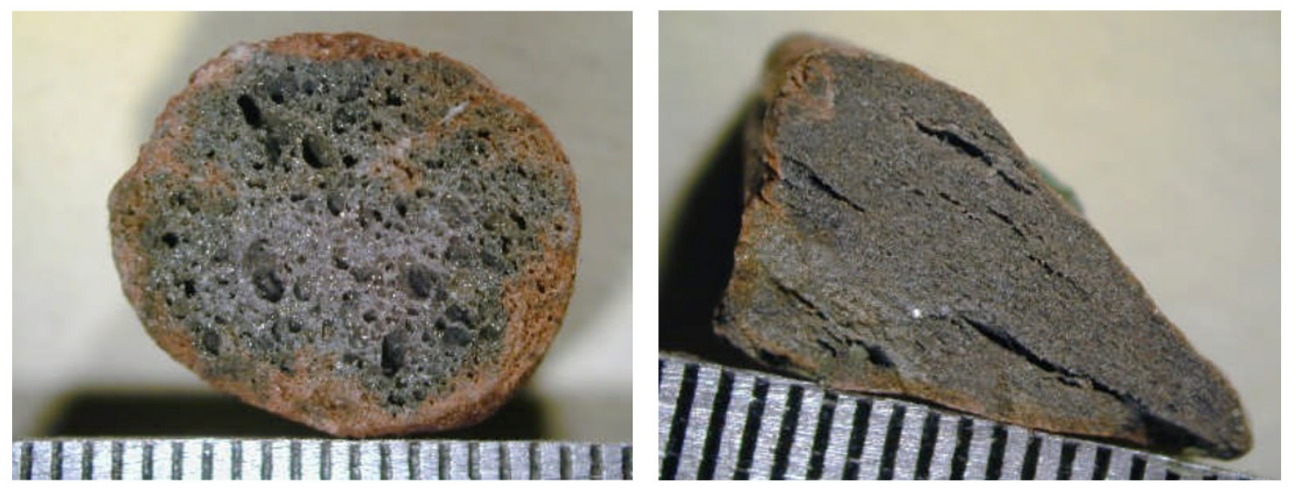

Figure 1. Typical sections of LWA [24]: a) Rounded and porous LWA, typical of expanded clay aggregates (4/10-550-A and 4/10-430-A) b) Angled and less porous LWA, corresponding to over $50 \%$ of the expanded shale aggregates (4/10-520-S and 4/8-750-S)

Table 1 presents the mass of broken/crushed grains, which are calculated based on a manual separation; and the shape index of the LWA, corresponding to the ratio between the aggregate's larger and smaller dimensions. The amount of broken/crushed grains varies significantly among the aggregate types, being on average more marked for expanded shale ones. Regarding the shape, the closer the Length/Thickness (L/T) ratio is to 1, more equidimensional and less flat will be the LWA. In this sense, the shape results confirm the visual observation (Figure 1), showing that clay aggregates usually have lower $\mathrm{L} / \mathrm{T}$ values than shale ones. Within each particle size range, the larger the grain diameter is, the less spherical is its form.

Table 1 Physical and geometrical properties of aggregates [22]

\begin{tabular}{ccccc}
\hline & $\mathbf{4} / \mathbf{1 0 - 5 5 0 - A}$ & $\mathbf{4 / 1 0 - 4 3 0 - A}$ & \multicolumn{4}{c}{$\mathbf{4 / 1 0 - 5 2 0 - S}$} & $\mathbf{4 / 8}-\mathbf{7 5 0 - S}$ \\
\hline Mass of broken grains (\%) & 7.38 & 1.85 & 19.21 & 6.68 \\
\hline Mean ratio Length/Thickness (L/T) & 1.33 & 1.57 & 1.92 & 2.20 \\
\hline Bulk Density $\left(\mathrm{kg} / \mathrm{m}^{3}\right)$ & 560.3 & 454.7 & 493.4 & 877.7 \\
\hline
\end{tabular}

Table 1 also presents the LWA's bulk densities. This is one of the most important properties of this material, since it influences the dead weight of LWAC structures, and it is used to estimate the aggregate's elastic modulus and 
mechanical strength by empirical relations. The studied aggregates have bulk densities ranging from $455 \mathrm{~kg} / \mathrm{m}^{3}$ to $878 \mathrm{~kg} / \mathrm{m}^{3}$. In average, expanded clay aggregates have lower densities than expanded shale aggregates, possibly due to their shape and pore system, which will influence other physical parameters.

Concerning the particle size distributions of the LWA, a narrow granular size distribution is observed. For 4/10-550-A, this theoretical sieve size through which $50 \%$ of the particles pass is $8.4 \mathrm{~mm}$; for $4 / 10-430-\mathrm{A}, 7.2 \mathrm{~mm}$; for $4 / 10-520-\mathrm{S}, 7.0 \mathrm{~mm}$; and for 4/8-750-S, $5.4 \mathrm{~mm}$. According to Ke et al. [22], the occurrence of powdery grains smaller than $2.5 \mathrm{~mm}$ is probably due to crushed coarser grains.

\subsection{Numerical simulation}

The FEM model simulated the LWAC in two phases: the mortar (m) and the LWA (a). From the aggregate's and the mortar's properties, the behavior of LWAC samples at 28 days was simulated when subjected to compressive load. The free processing software CAST3M was used, which includes built-in pre-processing and post-processing tools. CAST3M is an open source code developed by the French Atomic Energy Agency (CEA). It solves partial differential equations through the finite element method, allowing the incorporation and adaptation of models by the user. It employs a language based on object-oriented programming, named GIBIANE, and the objects are created using pre-defined operators, written in the language ESOPE [25].

The parameters used in the FEM simulation were:

- Compressive strength $\left(f_{m}\right)$ and Young's modulus $\left(E_{m}\right)$ of the mortar matrix (experimentally obtained by Ke et al. [23]);

- Tensile strength $\left(t_{m}\right)$ of the mortar, based on empirical correlations with its compressive strength proposed by Chust and Figueiredo [26];

- Volume fraction of lightweight aggregate adopted in the concrete's mixture (12.5\%, 25.0\%, 37.5\% and 45.0\%);

- Particle size distribution of the aggregates [24];

- Young's modulus of the LWA $\left(E_{a}\right)$, obtained empirically, based on its dry density [23];

- Compressive strength of the LWA $\left(f_{a}\right)$, obtained in an analytical inverse method by Ke et al. [23].

- Tensile strength $\left(t_{a}\right)$ of the LWA, from [22];

- For comparison purposes, compressive strength $\left(f_{c, \exp }\right)$ and Young's modulus $\left(E_{c, \text { exp }}\right)$ measured on hardened LWAC samples [23];

The FEM model considers a longitudinal cross-section of a standard cylindrical sample with $16 \mathrm{~cm}$ of diameter and $32 \mathrm{~cm}$ high (Figure 2). For computational efficiency, 1/4 of the section was used in this work, considering the boundary conditions of geometric symmetry of the sample. In this specimen, the LWA were modeled as perfect spheres randomly distributed within the homogeneous mortar matrix (Figure 3), with the same particle size distribution as the experimental program. The procedure to create $2 \mathrm{D}$ models from $3 \mathrm{D}$ spheres with the proper particle size distribution adopts image processing techniques described in references [27] and [28].

a)

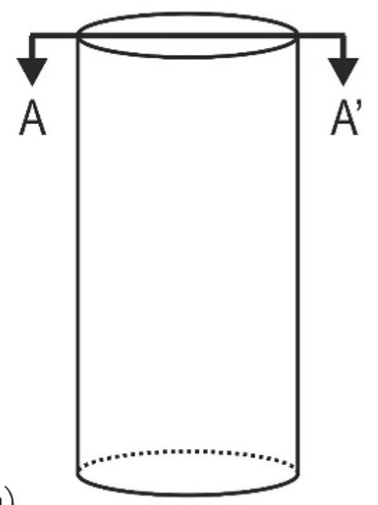

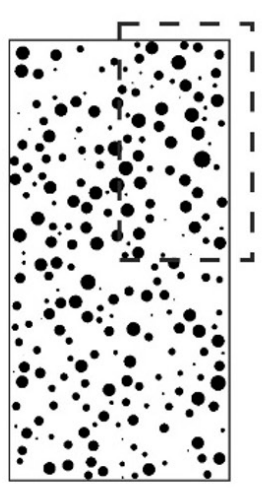

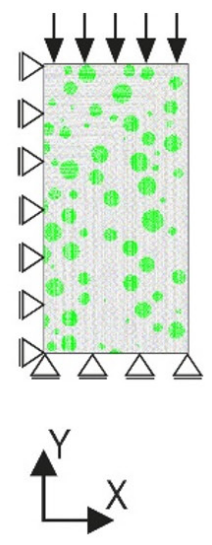

b)

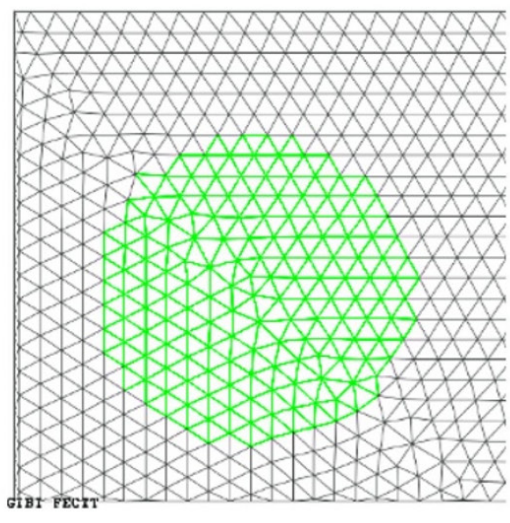

Figure 2 Numerical representation of one LWAC sample: (a) The geometry of the modeled LWAC sample (16-cm diameter and 32-cm height), from which a middle cross section was used; (b) Typical FE triangle mesh used; the round green circle representing the aggregate, surrounded by the mortar, in grey 

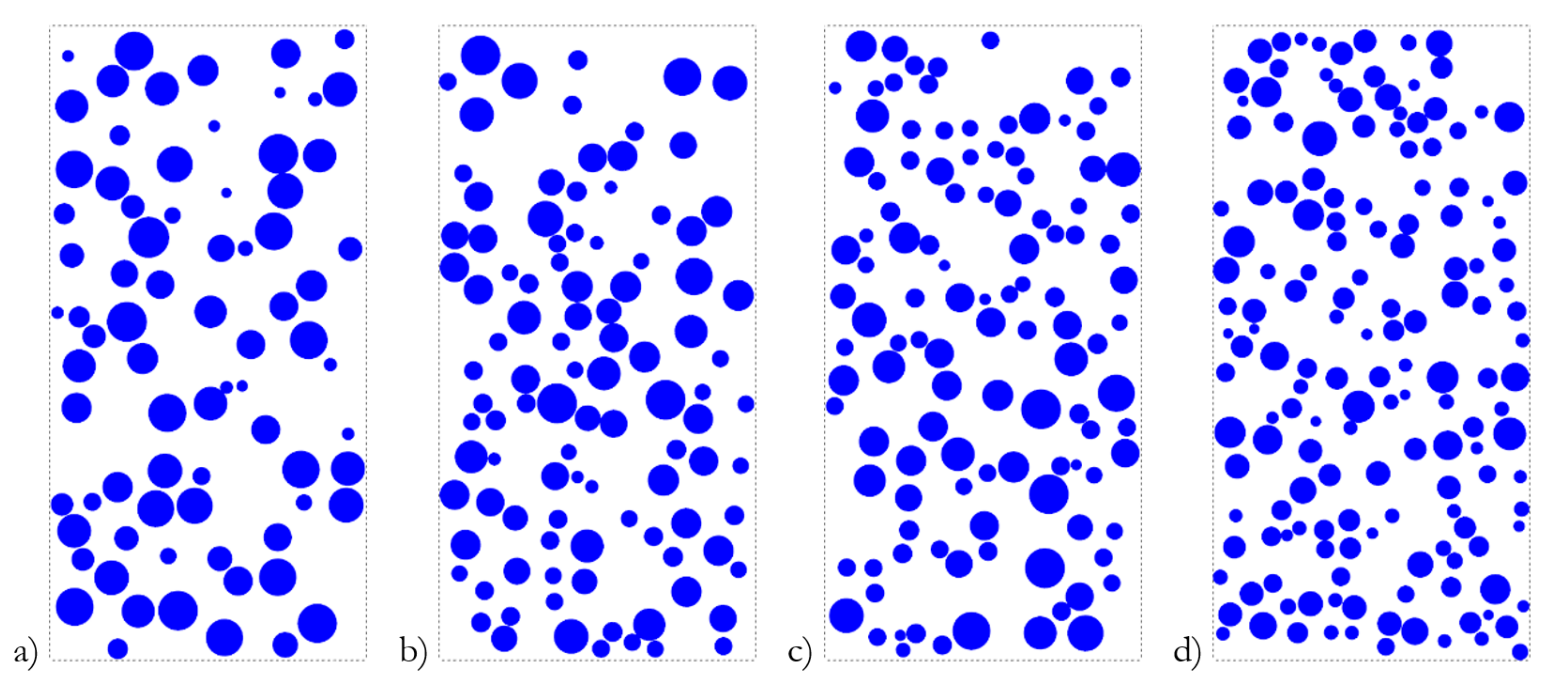

Figure 3 Examples of the longitudinal section of samples containing $25 \%$ of aggregates and following the particle size distribution of each type: (a) 4/10-550-A (b) 4/10-430-A (c) 4/10-520-S (d) 4/8-750-S

The authors highlight that an actual plane stress case would require prismatic samples. By using cylindrical samples, errors arising from this approach are reduced in the central region, marked with a hatch in Figure 4. The present work considers this area in the computational modeling. This geometric simplification was necessary due to the high level of processing cost demanded by a 3D model. This sensitivity analysis was performed by the authors [29], who observed similar results between the 2D and 3D simulations, with the latter taking 98 times longer.

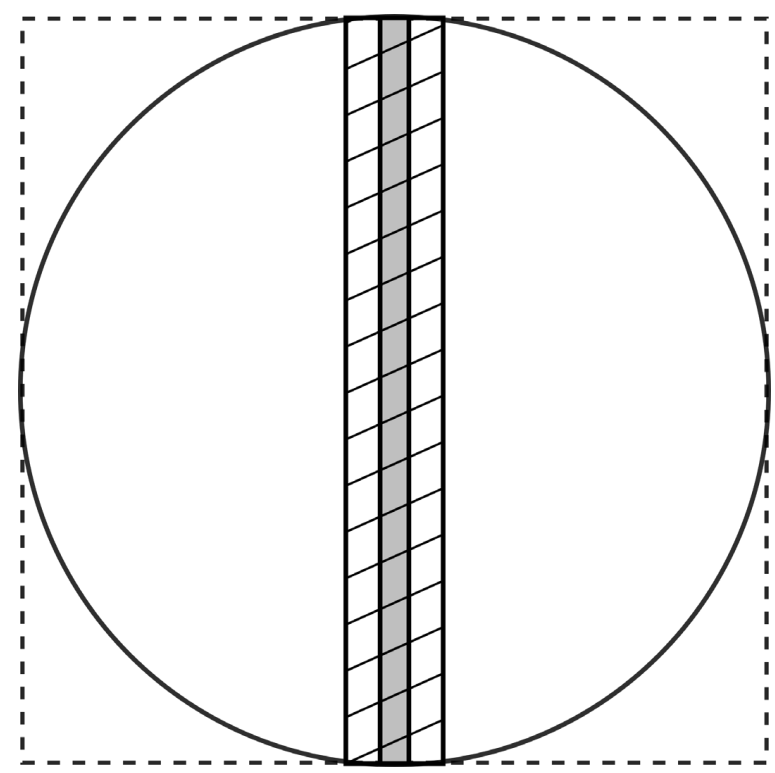

Figure 4 Top view of the cylindrical specimen. The hatched area representing where a plane stress simplification would incur in less distortions. The grey area corresponds in scale to the thickness adopted by the model.

Additionally, even in a 2D domain, the processor traditionally adopts a unit thickness to the modelled plane. However, the extrusion of circles from the 2D domain to 3D is a cylinder, and not a sphere. To reduce this imprecision, instead of a unit thickness, we adopted a value ( $t$ ) that would keep constant the volume of the maximum aggregate diameter $(1 \mathrm{~cm})$. By relating the spherical volume of the maximum aggregate diameter with the thickness of its respective cylindrical extrusion (Equation 1), a model thickness of $0.667 \mathrm{~cm}$ was adopted (Figure 4). 
$\frac{4}{3} \pi\left(\frac{1}{2}\right)^{3}=\pi\left(\frac{1}{2}\right)^{2} \mathrm{t}$

For both expanded clay and shale aggregates, the same strategy was applied, which considers the LWA's geometry as perfect spheres. The effectiveness of this choice will be discussed further on. To account for the dispersion of results, three models with random aggregate scattering (within the real particle size distribution) were generated from each synthetic sample.

An elastoplastic material behavior was adopted for the FEM simulations, with Drucker-Prager yield criterion [25]. Limits for compressive and tensile strength for each material were assumed according to the input parameters, and a perfect plastic yield was considered. The materials properties of aggregates and mortar adopted for the simulation and validation of these models are shown in Table 2 and Table 3 , respectively.

Table 2 Properties of the aggregates used in the numerical simulation

\begin{tabular}{|c|c|c|c|c|c|c|c|c|}
\hline \multirow{2}{*}{$\begin{array}{l}\text { Aggregates } \\
\text { Parameter }\end{array}$} & \multicolumn{2}{|c|}{ 4/10-550-A } & \multicolumn{2}{|c|}{ 4/10-430-A } & \multicolumn{2}{|c|}{ 4/10-520-S } & \multicolumn{2}{|c|}{ 4/8-750-S } \\
\hline & Mean & Std.Dv. & Mean & Std.Dv. & Mean & Std.Dv. & Mean & Std.Dv. \\
\hline$E_{a}(\mathrm{GPa})$ & 9.88 & 1.99 & 8.26 & 1.05 & 11.30 & 1.20 & 25.11 & 4.72 \\
\hline$f_{a}(\mathrm{MPa})$ & 23.40 & 5.93 & 19.90 & 4.26 & 28.33 & 6.74 & 53.43 & 17.68 \\
\hline$t_{a}(\mathrm{MPa})$ & 3.08 & 0.78 & 2.04 & 0.44 & 2.59 & 0.62 & 6.67 & 2.21 \\
\hline$E_{c, \exp }(\mathrm{GPa})$ & 23.58 & 4.53 & 22.42 & 4.15 & 24.24 & 4.22 & 29.97 & 3.35 \\
\hline$f_{c, \exp }(\mathrm{MPa})$ & 39.70 & 10.36 & 37.35 & 10.00 & 44.92 & 12.07 & 58.47 & 14.71 \\
\hline
\end{tabular}

Where $E_{a}$ - LWA's Young's modulus; $E_{m}$ - Mortar's Young's modulus; $f_{a}$ - LWA's compressive strength; $f_{m}$ - Mortar's compressive strength; $t_{a}$ - LWA's tensile strength; $t_{m}$ - Mortar's tensile strength; $E_{c, \text { exp }}$ - LWAC's Young's modulus; $f_{c, \text { exp }}$ - LWAC's compressive strength.

Table 3 Properties of the mortars used in the numerical simulation

\begin{tabular}{|c|c|c|c|c|c|c|}
\hline \multirow{2}{*}{$\begin{array}{c}\text { Mortars } \\
\text { Parameter }\end{array}$} & \multicolumn{2}{|c|}{ Normal } & \multicolumn{2}{|c|}{ High Performance } & \multicolumn{2}{|c|}{ Very High Performance } \\
\hline & Mean & Std. Dev. & Mean & Std. Dev. & Mean & Std. Dev. \\
\hline$E_{m}(\mathrm{GPa})$ & 28.59 & 1.16 & 33.18 & 0.68 & 35.40 & 0.46 \\
\hline$f_{m}(\mathrm{MPa})$ & 40.18 & 1.17 & 64.18 & 0.83 & 85.96 & 2.42 \\
\hline$t_{m}(\mathrm{MPa})$ & 3.52 & 0.33 & 4.42 & 0.19 & 4.98 & 0.50 \\
\hline$E_{c, \exp }(\mathrm{GPa})$ & 21.34 & 3.84 & 31.93 & 4.57 & 27.30 & 4.86 \\
\hline $\mathrm{f}_{\mathrm{c}, \exp }(\mathrm{MPa})$ & 33.72 & 5.98 & 43.85 & 9.87 & 55.89 & 14.92 \\
\hline
\end{tabular}

Where $E_{m}$ - Mortar's Young's modulus; $f_{m}$ - Mortar's compressive strength; $t_{m}$ - Mortar's tensile strength; $E_{c, \text { exp }}$ - LWAC's Young's modulus; $f_{c, \text { exp }}$ - LWAC's compressive strength.

To simulate the compressive strength test, a downward linear displacement of $0.5 \mathrm{~mm}$ was incrementally imposed on the upper surface up to $3.0 \%$ strain, which relates to the maximum stress value in a typical stress-strain curve obtained from a concrete sample. The compressive stress values were evaluated from the support conditions at the base of the sample.

In addition, to evaluate the performance results, the statistical parameter Mean Absolute Percentage Error (MAPE) was employed according to the mathematical definition given by Equation 2, where $n$ is the number of samples, $y_{\mathrm{i}}$ is the experimental value and $p_{i}$ is the numerical value.

$M A P E=\frac{1}{n} \sum_{i=1}^{n}\left(\left|\frac{y_{i}-p_{i}}{y_{i}}\right|\right)$

The MAPE statistical metric is dimensionless and provides an effective means of residual error compared to each observed value with their respective numerical value. The lower the MAPE values, the better the performance of the numerical model.

Another statistical parameter used in this work is the Pearson correlation coefficient $(r)$, defined by Equation 3 , which measures the power of association between two variables. It is dependent on the linear relationships between the numerical and experimental values. The closer the $r$ value is to 1, the better the association between the experimental and numerical values. 
$r=\left(\frac{\sum_{i=1}^{n}\left[\left(y_{i}-\bar{y}\right)\left(p_{i}-\bar{p}\right)\right]}{\sum_{i=1}^{n}\left(y_{i}-\bar{y}\right)^{2} \sum_{i=1}^{n}\left(p_{i}-\bar{p}\right)^{2}}\right)$

where $n$ is the number of samples, $y_{i}$ is the experimental value, $\bar{y}$ is the mean of experimental values, $p_{i}$ is the numerical value and $\overline{\mathrm{p}}$ is the mean of numerical values.

\section{RESULTS AND DISCUSSIONS}

Table 4 presents the mean results, standard deviations and MAPE of the numerical simulations of LWAC for each type of aggregate for the studied mechanical properties: Young's modulus $\left(E_{c}\right)$ and compressive strength $\left(f_{c}\right)$. When evaluating the MAPE, it is observed that the smallest error was obtained for the aggregate $4 / 8-750-\mathrm{S}\left(0.24 \%\right.$ for $E_{c}$ and $3.62 \%$ for $\left.f_{c}\right)$, and the most substantial error was obtained by aggregate $4 / 10-430-\mathrm{A}\left(4.57 \%\right.$ for $E_{c}$ and $11.19 \%$ for $f_{c}$ ). The $r$ values for the four aggregates and both mechanical properties were higher than 0.9677 , which indicates that there is a robust correlation between the experimental and numerical results.

Table 4 Numerical results of the mechanical properties (Young's modulus, $\mathrm{E}_{\mathrm{c}}$; and compressive strength, $\mathrm{f}_{\mathrm{c}}$ ) for each aggregate type; including MAPE and Pearson correlation coefficient (r) statistical parameters.

\begin{tabular}{|c|c|c|c|c|c|c|c|c|}
\hline \multirow{2}{*}{$\begin{array}{l}\text { Parameter } \\
\text { Aggregates }\end{array}$} & \multicolumn{4}{|c|}{$E_{c}(\mathrm{GPa})$} & \multicolumn{4}{|c|}{$f_{c}$ (MPa) } \\
\hline & Mean & Std. Dev & МАРЕ & $r$ & Mean & Std. Dev & МАРЕ & $r$ \\
\hline $4 / 10-550-\mathrm{A}$ & 22.69 & 4.44 & $3.84 \%$ & 0.9970 & 40.23 & 12.69 & $8.58 \%$ & 0.9699 \\
\hline 4/10-430-A & 21.50 & 4.44 & $4.57 \%$ & 0.9973 & 39.39 & 12.78 & $11.19 \%$ & 0.9677 \\
\hline $4 / 10-520-\mathrm{S}$ & 23.44 & 4.02 & $3.26 \%$ & 0.9964 & 45.04 & 13.13 & $4.76 \%$ & 0.9860 \\
\hline 4/8-750-S & 29.98 & 3.41 & $\underline{0.24 \%}$ & 0.9995 & 60.16 & 16.17 & $3.62 \%$ & 0.9974 \\
\hline
\end{tabular}

Figure 5 shows the numerical and experimental results of the LWAC properties represented in boxplot graphs. These graphs allow the visualization and evaluation of the position, dispersion, symmetry, and outliers of the data sets for each type of LWA. None of the properties presented significantly different results between the numerical and experimental values. On the left, Figure 5 shows that the quartiles of $E_{c}$ are positioned slightly below the quartiles of the experimental results, except for the 4/8-750-S aggregate, although all have similar dispersions. Whereas on Figure 5 right, the quartiles of the numerical results for $f_{c}$ are slightly more dispersed than the quartiles of the experimental results, without a clear tendency of underestimation or overestimation.
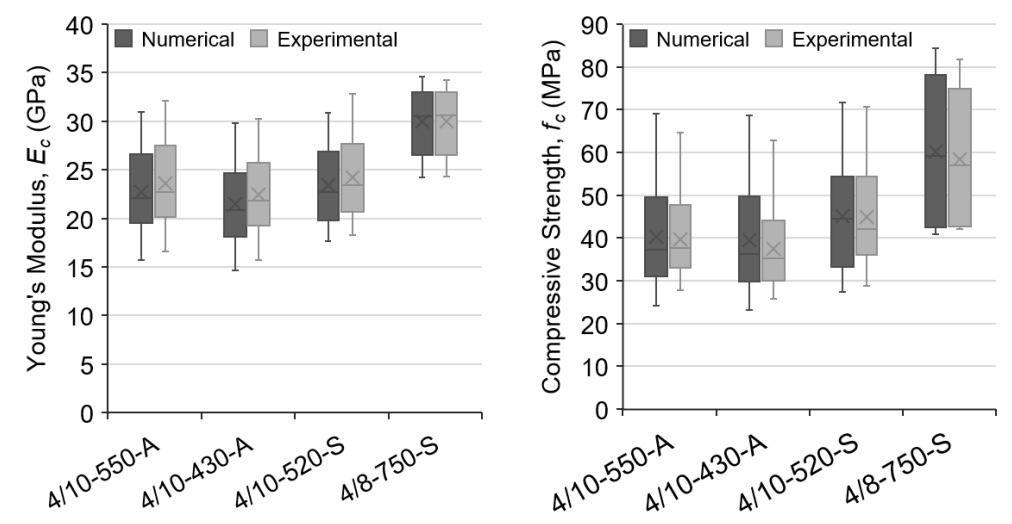

Figure 5 Numerical (dark grey) and experimental (light grey) results of the mechanical properties of LWAC for each type of LWA: left - Young's modulus; right - compressive strength.

Table 5 presents the statistical parameters MAPE and Pearson correlation coefficient $(r)$ for Young's modulus and compressive strength properties according to the aggregate material, expanded clay (A) and expanded shale (S). The $r$ values for the two types of aggregates in both mechanical properties were higher than 0.96 , which indicates that there 
is a robust correlation between the experimental and numerical results. Concerning MAPE values, results for expanded shale (S) were slightly better than those achieved for expanded clay (A). These last results indicate that, for the proposed model, the actual geometry of the LWA is not a crucial parameter. Initially, it could be expected that the rounded expanded clay aggregates (A) would incur in lower errors since the developed FE mesh considers LWA as spheres. However, uncertainties concerning the input parameters presented in Table 2, as well as imperfections in the adopted elastoplastic model, probably have an essential role in the prediction of the mechanical properties through the presented method.

Table 5 Statistical parameters of the correlation between the numerical and experimental data of each type of aggregate for Young's modulus $\left(\mathrm{E}_{\mathrm{c}}\right)$ and compressive strength $\left(\mathrm{f}_{\mathrm{c}}\right)$.

\begin{tabular}{|c|c|c|c|c|}
\hline \multirow{2}{*}{$\begin{array}{c}\text { Parameter } \\
\text { Aggregate type }\end{array}$} & \multicolumn{2}{|c|}{$E_{c}$} & \multicolumn{2}{|c|}{$f_{c}$} \\
\hline & $\mathbf{r}$ & MAPE & $\mathbf{r}$ & MAPE \\
\hline Expanded clay (A) & 0.9963 & $4.21 \%$ & 0.9654 & $9.89 \%$ \\
\hline Expanded shale (S) & 0.9955 & $1.75 \%$ & 0.9943 & $\underline{4.19 \%}$ \\
\hline
\end{tabular}

In turn, Figure 6 shows the linear regression from the experimental and numerical data of expanded clay (A) and expanded shale (S) for Young's modulus (Figure 6 left) and compressive strength (Figure 6 right). Those graphs confirm a reliable correlation between numerical and experimental data.
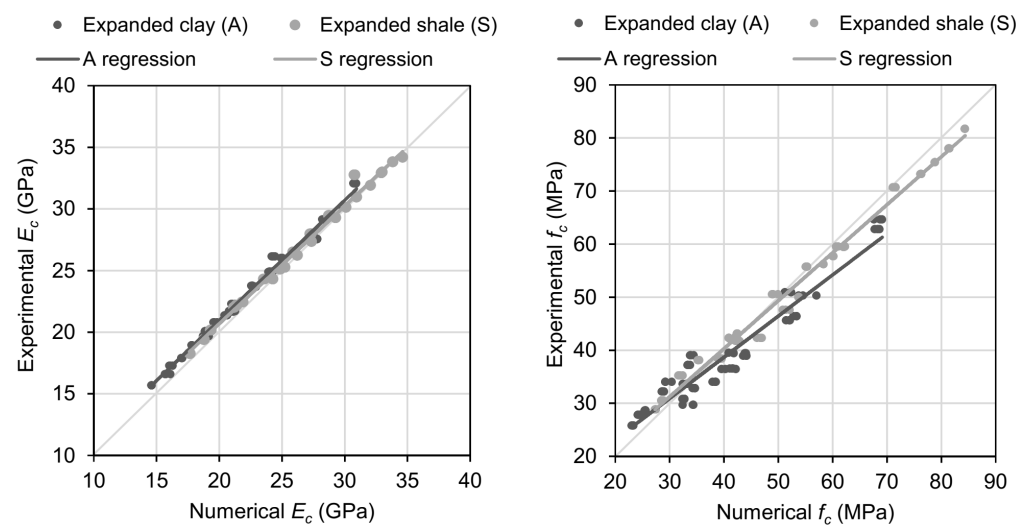

Figure 6 Comparison of the linear regression models for expanded clay (A) and expanded shale (S) aggregates and each mechanical property: left - Young's modulus; right - compressive strength.

When evaluating the numerical results according to the relative volume of the aggregates, it is observed in Table 6 that the highest MAPE value for Young's modulus $\left(E_{c}\right)$ was $3.58 \%$ for $45.0 \%$ of LWA and the lowest MAPE was $2.36 \%$ for $25.0 \%$ LWA. For compressive strength $\left(f_{c}\right)$, the highest MAPE value was $8.13 \%$ to $25.0 \%$ LWA, and the lowest MAPE was $6.11 \%$ to $12.5 \%$ LWA. Thus, there was no clear trend in relation to the volume of aggregates.

Table 6 Numerical results of the mechanical properties (Young's modulus, $\mathrm{E}_{\mathrm{c}}$; and compressive strength, $\mathrm{f}_{\mathrm{c}}$ ) for each aggregate volume; including MAPE and Pearson correlation coefficient (r) statistical parameters.

\begin{tabular}{|c|c|c|c|c|c|c|c|c|}
\hline \multirow{2}{*}{$\begin{array}{c}\text { Parameter } \\
\text { Volume } \\
\end{array}$} & \multicolumn{4}{|c|}{$E_{c}(\mathrm{GPa})$} & \multicolumn{4}{|c|}{$f_{c}(\mathrm{MPa})$} \\
\hline & Mean & Std. Dev. & MAPE & $r$ & Mean & Std. Dev & MAPE & $r$ \\
\hline $12.5 \%$ & 29.25 & 3.00 & $2.60 \%$ & 0.9698 & 54.00 & 13.87 & $6.11 \%$ & 0.9846 \\
\hline $25.0 \%$ & 26.16 & 3.62 & $2.36 \%$ & 0.9973 & 46.56 & 13.18 & $8.13 \%$ & 0.9738 \\
\hline $37.5 \%$ & 23.14 & 4.51 & $\overline{3.39 \%}$ & 0.9986 & 40.98 & 13.43 & $\overline{7.46 \%}$ & 0.9851 \\
\hline $45.0 \%$ & 21.66 & 4.92 & $3.58 \%$ & 0.9988 & 38.90 & 12.56 & $6.45 \%$ & 0.9886 \\
\hline
\end{tabular}

Additionally, the standard deviations for the numerical results grouped by volume (Table 6) are very close to those grouped by aggregates (Table 2). The highest standard deviation value for Young's modulus was $4.53 \mathrm{GPa}$ for the 
aggregate 0/10-550-A and 4.92 GPa for 45.0\% LWA; and the lowest standard deviation was 3.35 GPa for 4/8-750-S and $3.00 \mathrm{GPa}$ for $12.5 \% \mathrm{LWA}$. On the other hand, the highest standard deviation value for compressive strength was 14.71 GPa for 4/8-750-S and $13.87 \mathrm{GPa}$ for $12.5 \% \mathrm{LWA}$; and the lowest one was $10.00 \mathrm{GPa}$ for $4 / 10-430-\mathrm{A}$ and $12.56 \mathrm{GPa}$ for $45.0 \% \mathrm{LWA}$. Therefore, these values indicate that the dispersion of the numerical results grouped by volume and by aggregates are very close. Thus, we conclude that our modeling has no bias concerning these parameters.

Finally, a similar analysis was performed with the numerical data grouped by mortar type (Table 7 and Figure 7). The highest MAPE value for the modulus of elasticity was 3.23\%, for normal mortar (M8), and the lowest MAPE was $2.80 \%$, for high-performance mortar (M9). For compressive strength, the highest MAPE value was $7.80 \%$ for normal mortar (M8), and the lowest MAPE was 5.96\% to high-performance mortar (M9). Figure 7 shows in boxplots the experimental and numerical data of the mechanical properties grouped by mortar type, which allows the visualization of the proximity of the results predicted by the numerical models. Therefore, the assortment by mortar types also did not present a clear tendency of underestimation or overestimation; but similar mean values and dispersion.

Table 7 Numerical results of the mechanical properties (Young's modulus, $E_{c}$; and compressive strength, $f_{c}$ ) grouped under mortar type; including MAPE and Pearson correlation coefficient $(r)$ statistical parameters.

\begin{tabular}{|c|c|c|c|c|c|c|c|c|}
\hline \multirow{2}{*}{$\frac{\text { Parameter }}{\text { Mortar Type }}$} & \multicolumn{4}{|c|}{$E_{c}(\mathrm{GPa})$} & \multicolumn{4}{|c|}{$f_{c}(\mathrm{MPa})$} \\
\hline & Mean & Std Dev & MAPE & $r$ & Mean & Std Dev & MAPE & $\bar{r}$ \\
\hline Normal (M8) & 21.89 & 3.81 & $\underline{3.23 \%}$ & 0.9938 & 34.69 & 5.93 & $\underline{7.80 \%}$ & 0.9818 \\
\hline High Performance (M9) & 25.44 & 4.38 & $\underline{2.80 \%}$ & 0.9979 & 44.12 & 10.11 & $\underline{5.96 \%}$ & 0.9780 \\
\hline Very High Performance (M10) & 27.83 & 4.88 & $2.91 \%$ & 0.9946 & 56.42 & 15.71 & $7.36 \%$ & 0.9954 \\
\hline
\end{tabular}
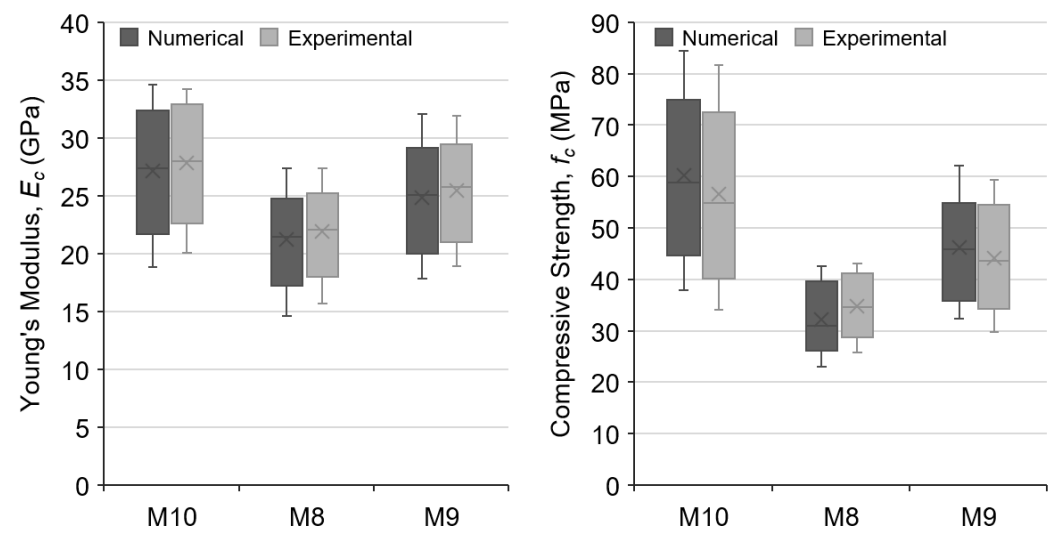

Figure 7 Numerical (dark grey) and experimental (light grey) results of the mechanical properties of LWAC grouped under mortar type (M8 - normal, M9 - high performance and M10 - very high performance): left - Young's modulus; right - compressive strength.

\section{CONCLUSIONS}

The present work evaluates the accuracy of a numerical FEM simulation in predicting the compressive strength and Young's modulus of LWAC. The capacity of generalization of the presented method was also investigated. To this purpose, the compressive behavior of 48 LWAC formulations was simulated, and the achieved numerical results were compared with their experimental counterparts.

Overall, a reasonable agreement was found for both analyzed mechanical properties. The larger errors for compressive strength and Young's modulus predictions were $11.19 \%$ and $4.57 \%$, respectively, which is considered a satisfactory result. Not only the mean results but also the dispersion of the values were very similar between the numerical and experimental data. The results of the linear regression and the Pearson correlation coefficient $(r)$ also indicate that there is a strong correlation between the experimental values and the numerical values, since the $r$ value was greater than 0.96 for all types of aggregates and mechanical properties.

In general, the MAPE error values were lower for the irregular-shaped shale aggregates (S) for both Young's modulus ( $4.21 \%$ for expanded clay versus $1.75 \%$ for expanded shale) and compressive strength $(9.89 \%$ for expanded 
clay versus $4.19 \%$ for expanded shale). No clear trend of error was identified in relation to the volume of aggregates in the LWAC or to the mortar types.

In conclusion, the simplification to spherical aggregates (circles in the 2D model) has shown satisfactory results, despite some of the aggregates being roughly irregular. In addition, the efficacy of the 2D model, which require less computational resources and shorter simulation time, was demonstrated. This result indicates that the 2D model ensures that the aggregate volume and particle size distribution are very close to the actual percentage of the experimental specimens, and that the distortions caused by the cylindrical shape of the real specimens are negligible in the central area adopted for the simulations.

These results encourage further applications with more complex geometrical aspects to improve the mix design and safety of LWAC structures. In conclusion, the prediction of the mechanical properties by the FEM models developed here is a feasible contribution to the mixture design of LWAC.

\section{ACKNOWLEDGEMENTS}

We gratefully acknowledge the agencies CAPES (Coordenação de Aperfeiçoamento de Pessoal de Nível Superior, Finance Code 001 - scholarship and PROCAD 88881.068530/2014-0), FAPEMIG (Fundação de Amparo à Pesquisa do Estado de Minas Gerais, projects APQ-01935-16 and PPM-00106-17), CNPq (Conselho Nacional de Desenvolvimento Científico e Tecnológico, projects 423058/2016-9-APQ and 306686/2015-5-PQ, 311576/2018-4-PQ), UFJF (Universidade Federal de Juiz de Fora, scholarship), and UFOP (Universidade Federal de Ouro Preto) for the infrastructure and financial support.

The authors declare that there is no conflict of interest.

\section{REFERENCES}

[1] K. W. Day, J. Aldred, and B. Hudson, Concrete Mix Design, Quality Control and Specification. Boca Raton: CRC Press, 2013.

[2] A. M. Neville and J. J. Brooks, Concrete Technology. Philadelphia: Trans-Atlantic Publications, 2010.

[3] American Society for Testing and Materials, Standard Terminology Relating to Concrete and Concrete Aggregates, ASTM C125, 2018.

[4] Associação Brasileira de Normas Técnicas, Concrete for Structural Use - Density, Strength and Consistence Classification, NBR 8953, 2015.

[5] W. G. Moravia, A. G. Gumieri, and W. L. Vasconcelos, "Fator de eficiência e modulo de elasticidade do concreto leve produzido com argila expandida," Rev. IBRACON Estrut. Mater., vol. 3, no. 2, pp. 195-204, 2010.

[6] B. C. D. Santis and J. A. Rossignolo, "Influência dos agregados leves de argila calcinada nas propriedades mecânicas de concretos estruturais," Materia, vol. 20, no. 2, pp. 399-406, 2015.

[7] B. C. de Santis and J. A. Rossignolo, "Avaliação da influência de agregados leves de argila calcinada no desempenho de concretos estruturais," Ambient. Constr., vol. 14, no. 4, pp. 21-32, 2014.

[8] P. Mehta and P. J. M. Monteiro, Concrete: Microstructure, Properties, and Materials, 2nd ed. São Paulo: IBRACON, 2014.

[9] A. Bentur, S. I. Igarashi, and K. Kovler, "Prevention of autogenous shrinkage in high-strength concrete by internal curing using wet lightweight aggregates," Cement Concr. Res., vol. 31, no. 11, pp. 1587-1591, 2001.

[10] D. P. Bentz and K. A. Snyder, "Protected paste volume in concrete: Extension to internal curing using saturated lightweight fine aggregate," Cement Concr. Res., vol. 29, no. 11, pp. 1863-1867, 1999.

[11] J. A. Bogas and A. Gomes, "Compressive behavior and failure modes of structural lightweight aggregate concrete-Characterization and strength prediction," Mater. Des., vol. 46, pp. 832-841, 2013.

[12] M. H. Zhang and O. E. Gjvorv, "Mechanical properties of high-strength lightweight concrete," ACI Mater. J., vol. 88, no. 3, pp. 240247, 1991.

[13] C. C. Yang and R. Huang, "Approximate strength of lightweight aggregate using micromechanics method," Adv. Cement Base. Mater., vol. 7, no. 3-4, pp. 133-138, 1998.

[14] I. B. Topcu and M. Sarıdemir, "Prediction of compressive strength of concrete containing fly ash using artificial neural networks and fuzzy logic," Comput. Mater. Sci., vol. 41, no. 3, pp. 305-311, 2008.

[15] R. Le Roy, E. Parant, and C. Boulay, "Taking into account the inclusions' size in lightweight concrete compressive strength prediction," Cement Concr. Res., vol. 35, no. 4, pp. 770-775, 2005.

[16] I. C. Yeh, "Modeling of strength of high-performance concrete using artificial neural networks," Cement Concr. Res., vol. 28, no. 12, pp. 1797-1808, 1998.

[17] F. Altun, Ö. Kişi, and K. Aydin, "Predicting the compressive strength of steel fiber added lightweight concrete using neural network," Comput. Mater. Sci., vol. 42, no. 2, pp. 259-265, 2008. 
[18] M. M. Alshihri, A. M. Azmy, and M. S. El-Bisy, "Neural networks for predicting compressive strength of structural light weight concrete," Constr. Build. Mater., vol. 23, no. 6, pp. 2214-2219, 2009.

[19] A. Bonifácio, J. Mendes, M. Farage, F. Barbosa, C. Barbosa, and A. Beaucour, "Application of Support Vector Machine and Finite Element Method to predict the mechanical properties of concrete," Lat. Am. J. Solids Struct., vol. 16, no. 7, e205, 2019.

[20] H. Z. Cui, T. Y. Lo, S. A. Memon, F. Xing, and X. Shi, "Analytical model for compressive strength, elastic modulus and peak strain of structural lightweight aggregate concrete," Constr. Build. Mater., vol. 36, pp. 1036-1043, 2012.

[21] F. S. Barbosa, M. C. R. Farage, A. L. Beaucour, and S. Ortola, "A Methodology to Evaluate Elastic Modulus of LightweightAggregate Concrete," ACI Mater. J., vol. 113, no. 1, 2016.

[22] Y. Ke, A. L. Beaucour, S. Ortola, H. Dumontet, and R. Cabrillac, "Influence of volume fraction and characteristics of lightweight aggregates on the mechanical properties of concrete," Constr. Build. Mater., vol. 23, no. 8, pp. 2821-2828, 2009.

[23] Y. Ke, S. Ortola, A. L. Beaucour, and H. Dumontet, "Micro-stress analysis and identification of lightweight aggregate's failure strength by micromechanical modeling," Mech. Mater., vol. 68, pp. 176-192, 2014.

[24] Y. Ke, Caractérisation du Comportement Mécanique des Bétons de Granulats Légers: Expérience. Cergy: Univ. Cergy-Pontoise, 2008.

[25] Commissariat a l'Energie Atomic, "Notices | cast3m - mode." 2003. http://wwwcast3m.cea.fr/index.php?page=notices\&notice=MODE (accessed Aug. 15, 2016).

[26] C. R. Chust and J. R. Figueiredo Fo., Cálculo e Detalhamento de Estruturas Usuais de Concreto Armado. São Carlos: EdUFSCar, 2004.

[27] F. S. Barbosa, M. C. R. Farage, A. L. Beaucour, and S. Ortola, "Evaluation of aggregate gradation in lightweight concrete via image processing," Constr. Build. Mater., vol. 29, pp. 7-11, 2012.

[28] F. S. Barbosa, A. L. Beaucour, M. C. R. Farage, and S. Ortola, "Image processing applied to the analysis of segregation in lightweight aggregate concretes," Constr. Build. Mater., vol. 25, no. 11, pp. 3375-3381, 2011.

[29] A. Bonifácio, "Estratégia computacional para avaliação de propriedades mecânicas de concreto de agregado leve,” Ph.D. dissertation, Univ. Fed. Juiz de For a, Juiz de Fora, 2017.

Author contributions: Aldemon Lage Bonifácio: Software, Formal analysis, Investigation. Julia Castro Mendes: Visualization, Writing - Original Draft. Michèle Cristina Resende Farage: Conceptualization, Methodology, Supervision, Writing - Review \& Editing, Project administration. Flávio de Souza Barbosa: Conceptualization, Methodology, Supervision, Writing - Review \& Editing. Anne-Lise Beaucour: Resources.

Editors: Bernardo Tutikian, José Luiz Antunes de Oliveira e Sousa, Guilherme Aris Parsekian. 